\title{
REPRESENTAÇÕES SOCIAIS DA FORMAÇÃO DO GRADUADO EM MODA POR EMPRESÁRIOS DO SETOR
}

\section{SOCIAL REPRESENTATIONS OF THE GRADUATION IN FASHION BY ENTREPRENEURS IN THIS SECTOR}

\author{
Rose Mary Mariano Rodrigues ${ }^{1}$, Rita de Cássia Pereira Lima ${ }^{2 *}$ \\ ${ }^{1}$ Mestre em Educação, consultora de empresas, Rio de Janeiro, RJ, Brasil, rosemary.mariano@gmail.com \\ 2 Doutora em Educação, Programa de Pós-Graduação em Educação da Universidade Estácio de Sá (Unesa-RJ), Rio de Janeiro, RJ, \\ Brasil, ritaplima2008@gmail.com \\ *Autor de correspondência
}

\section{Resumo}

O objetivo do estudo é investigar representações sociais da formação do graduado em Moda por empresários do setor no Rio de Janeiro. A pesquisa fundamentou-se na Teoria das Representações Sociais (TRS) e em estudos do campo da moda. Foram entrevistados 20 empresários de moda, sendo 10 com formação em Moda (Grupo 1) e 10 sem essa formação (Grupo 2). O material das entrevistas foi analisado com apoio da análise de conteúdo temática, complementada com repostas às seguintes questões: 1) "Se você fosse diretor (a) de uma escola de formação em Moda, como seria o seu curso?"; e 2) "O que vem à sua mente quando eu digo 'primeira imagem do graduado em Moda'?". A análise do conjunto desse material permitiu a proposição de um modelo figurativo da representação social da formação do graduado em Moda para cada um dos grupos. Para o Grupo I, a representação se objetiva em "insuficiência na formação do graduado em Moda" e para o Grupo 2 em "aprendizagem acontece no mundo do trabalho", podendo por vezes prescindir da formação acadêmica. Os resultados apontaram para o pouco diálogo entre cursos de graduação em Design de Moda e o empresariado do setor, contudo, mostraram possibilidades de aproximação entre essas duas áreas, universidade e mundo do trabalho.

Palavras-chave: Representações Sociais. Moda. Empresários. Graduação em Moda.

\begin{abstract}
The aim of the study was to investigate the social representations of the graduation in fashion by entrepreneurs in the sector in Rio de Janeiro. The research was based on the theory of social Representations (TRS) and studies in the field of fashion. Twenty fashion entrepreneurs were interviewed, 10 with training in the area (Group 1) and 10 without this formation (Group2). The material of the interviews was analyzed with the support of thematic content analysis. For the Interviewed, two questions were proposed that complemented the analysis: 1) "If you were a director of a fashion training school, what would your course be like?"; and 2) "What comes to your mind when I talk 'first image of the Graduate in fashion '?". The analysis of the set of this material allowed the proposition of a figurative model of the social representation of the graduation in fashion for each group where, the main conclusion concerning Group I is the "Insufficiency in training" and for Group II "Learning happens in the world of work", and may sometimes dispense with academic training. The results pointed to the little dialogue between graduation courses in fashion Design and the industry entrepreneurs, however, showed possibilities of approximation between these two parties, University and entrepreneurs.
\end{abstract}

Keywords: Social Representations. Fashion. Businessmen. Fashion Graduation

(C)NIS-MG. All rights reserved. 


\section{INTRODUÇÃO}

A moda está presente no cotidiano do ser humano, influenciando sua busca por personalização, construção de sua identidade e conquista do espaço que ocupa. Um dos elementos definidores da moda é a constante mudança na utilização de formas, materiais, ornamentações e cores. Para Lipovetsky $(2008$, p. 39), o reconhecimento da moda surge no final da Idade Média, transcendendo o desejo de exibir a classe social à qual pertenciam os sujeitos e passando a ser entendida como "um vetor de individualização narcísica, um instrumento do culto estético do Eu".

O conceito de moda e sua mutabilidade (BORGES, 2014), independentemente do período em que foi estabelecido, sempre foi focado mais especificamente no vestuário, exercendo influência tanto sobre o público feminino como o masculino. Segundo Hollander (1996), a moda deve seu poderio à forma pela qual pode fazer com que cada pessoa, tanto mulheres como homens, se sintam exclusivas, mesmo usando peças iguais ou similares àquelas utilizadas por outras pessoas.

O estudo da moda e a formação profissional para este campo iniciou-se em 1841, em Paris, por meio da criação da primeira escola de Moda no mundo, a École Supérieure des Arts et Techniques de la Mode (ESMOD). De acordo com Aguiar (2015), no Brasil a formação educacional por meio de cursos direcionados para a área da concepção de modelos de moda demorou a ser iniciada. Foi somente no século XX que surgiram os primeiros cursos para esta área.

Com direcionamento da promoção do ensino profissionalizante, na década de 1940 foi criado o Serviço Nacional de Aprendizagem Industrial (SENAI), que tinha como premissa a formação de profissionais para a indústria nacional. O serviço era custeado e monitorado pelas indústrias, juntamente com o Estado (CUNHA, 2000). No Rio de Janeiro, campo desse estudo, para atender à demanda da indústria do vestuário, o SENAI criou a Escola Técnica da Indústria Química e Têxtil (ETIQT). A partir da década de 1980, esta escola passa a se chamar Centro de Tecnologia da Indústria Química e Têxtil (CETIQT).

Essas instituições de formação profissional estavam voltadas para o ensino da construção das peças e para a organização fabril, e nesse período a participação do empresariado na constituição dos cursos era relevante. Eles eram sujeitos ativos que influenciavam na organização do programa a ser ensinado, bem como na duração de cada treinamento. A formação era então direcionada para atendimento das indústrias, carentes de mão de obra.

Na segunda metade da década de 1980 , as indústrias de confecção brasileiras tiveram crescimento significativo, com aumento também de exigência por uma gama maior de número de modelos ofertados aos consumidores, com menores ciclos de vida desses produtos. Essa demanda exigiu maior quantidade de profissionais qualificados e maior conhecimento acadêmico dentro do campo da moda, abrindo espaço para cursos no Ensino Superior (BORGES, 2014).

O primeiro curso superior voltado para essa área foi implantado em 1987, em São Paulo, pela Faculdade Santa Marcelina. No Rio de Janeiro, os primeiros cursos de graduação surgiram a partir da década de 1990, sendo a Universidade Veiga de Almeida a pioneira, em 1995. Em menos de trinta anos, o Brasil se tornou o país com o maior número de cursos voltados para a área, distribuídos em quase todo o território nacional, perfazendo em 2016 um total de 179 cursos de graduação em Moda (ABRAVEST, 2016).

Essa expressiva quantidade de cursos de graduação em Moda se deve ao crescimento das confecções e da necessidade de se criar um diferencial nos produtos comercializados que 
passaram a não ser somente copiados ou trazidos da Europa, mas desenvolvidos dentro das empresas, visando a consolidar a identidade brasileira no campo da moda. As universidades assumiram o papel de formação, antes delegado aos empresários e às suas organizações, constituindo desta forma três partes importantes para a área: o Estado, as universidades e os empresários.

As instituições de ensino superior em Moda vêm passando por diversas mudanças pois, em 2002, o Ministério de Educação (MEC) iniciou o processo de análise para revisão das Diretrizes Curriculares Nacionais dos cursos de graduação de nível superior, entre eles o Design. Em 2004, na Resolução CNE/CES n.5, foram aprovadas as Diretrizes Curriculares Nacionais do Curso de Graduação em Design e no parágrafo 5, item II (conteúdos específicos), há menção a estudos do vestuário (BRASIL, 2004). Desta maneira, algumas universidades alteraram seus cursos de graduação em Moda para graduação em Design de Moda, áreas que não se relacionavam até esse momento. O design, cuja tradução é desenho industrial, remete a questões objetivas do produto, sem considerar itens que dizem respeito ao sujeito, tais como preferências, gostos e conteúdos simbólicos (CHRISTO, 2008).

Diferentemente do design, a moda só pode ser concebida a partir desses fatores, não existindo concepção de moda sem conhecimento prévio do sujeito. Apesar dessas características, moda e design passaram a se complementar. Quanto aos projetos pedagógicos e currículos, as instituições de ensino em Moda ajustaram seus conteúdos curriculares a fim de adequá-los às Diretrizes Curriculares Nacionais do Curso de Graduação em Design, possibilitando ao aluno trabalhar em outras empresas que não integram exclusivamente o ramo da confecção do vestuário.

A aproximação entre moda e design permitiu ao estilista sair da "guetização" do papel de couturier, oficializando uma identidade profissional diferente, do designer industrial de produtos de vestuário (CALANCA, 2011). Sob o ponto de vista do profissional a ser formado, a associação entre esses cursos apresenta aspectos também positivos. Um deles é a expansão da empregabilidade dos alunos egressos, que passam a ter a formação necessária para atuar em áreas como fotografia, mobiliário, programação visual.

Nesse panorama em que desde os anos de 1980 os empresários passaram a ter menos participação na formação em Moda, nossa suposição é que atualmente existe pouco diálogo entre eles e os cursos de formação no Ensino Superior. Apesar de vários projetos pedagógicos dos cursos de Design de Moda informarem que um de seus objetivos é a preparação do aluno para o mundo do trabalho, as instituições de ensino superior priorizam sua conformidade em relação às diretrizes governamentais. Muitas vezes não há relação entre as propostas acadêmicas e as expectativas do empresariado que futuramente empregará os profissionais de moda.

Poucos trabalhos acadêmicos, contudo, tratam da temática. Essa lacuna provocou o interesse pelo presente estudo, que pretende dar destaque às significações construídas por empresários a respeito da formação do graduado em Moda, mais especificadamente em Design de Moda, tendo como fundamentação a Teoria das Representação Sociais (TRS). Diante desse panorama, o objetivo do estudo é investigar representações sociais elaboradas por empresários do setor da moda do Rio de Janeiro a respeito da formação do graduado no curso de Design de Moda. 


\section{FUNDAMENTAÇÃO TEÓRICA}

A TRS se propõe a compreender fenômenos envolvendo a relação entre o homem e o meio com o qual ele interage. Alves-Mazzotti (2008, p. 20-21) afirma que o estudo de representações sociais é relevante para se conhecer "como se formam e como funcionam os sistemas de referência que utilizamos para classificar pessoas e grupos e para interpretar os acontecimentos da realidade cotidiana". De acordo com Moscovici (2015, p. 58), essa teoria visa a "explicar fenômenos envolvendo o homem e seu ambiente social, tornando algo desconhecido em familiar, ancorados em valores, crenças e teorias".

Atento às articulações entre representações e ações coletivas, Moscovici (2012) defende a ideia de que as representações sociais são forças constitutivas da realidade. Elas dão sentido ao mundo, classificando os elementos do real e definindo formas de leitura dessa mesma realidade. Para o autor:

Todos os sistemas de classificação, todas as imagens e todas as descrições que circulam dentro de uma sociedade, mesmo as descrições científicas, implicam um elo de prévios sistemas e imagens, uma estratificação na memória coletiva e uma reprodução na linguagem [...] (MOSCOVICl, 2015, p. 37).

A importância dada à ação dos indivíduos na TRS também é salientada por Almeida et al. (2014, p. 135). Para as autoras, representações sociais podem ser compreendidas como "uma forma de conhecimento de senso comum e socialmente partilhado, tem em seu bojo a ideia de um conhecimento construído por um sujeito ativo em íntima interação com um objeto culturalmente construído [....".

De acordo com Moscovici (2012, p. 47), as representações sociais "são conjuntos dinâmicos, seu estatuto sendo o da produção de comportamentos e de relações com o ambiente, da ação que modifica uns e outros, e não a reprodução de comportamentos ou relações, como reação a um dado estímulo externo".

Em sua teoria, Moscovici propõe uma estrutura para as representações sociais. Elas teriam duas faces indissociáveis, como os dois lados de uma moeda. Essas faces são a "figura" (ou face figurativa) e sua respectiva "significação" (ou face simbólica), sendo que uma não existe sem a outra. De acordo com o autor, "a representação transmite a qualquer figura um sentido e a qualquer sentido, uma figura" (MOSCOVICl, 2012, p. 60).

Segundo Moscovici (2012, p. 100), na formação das representações sociais intervêm dois processos, a objetivação e a ancoragem, que de certo modo estão associados à relação entre figura e significado. No estudo aqui apresentado, que adotou a perspectiva sociogenética da TRS, foram considerados esses dois processos, que têm a função de conferir familiaridade àquilo que era inicialmente estranho ao sujeito. A objetivação é uma operação que materializa a palavra, tornando tangível o intangível. Ao transformar o abstrato em algo concreto, apoiamo-nos em concepções já familiares e consolidadas, o que facilita a compreensão, mas implica certa perda informativa, tendo em vista a "simplificação". Ela torna real um esquema conceitual, ao "substituir uma imagem por sua contrapartida material, resultado que tem primeiramente um alcance cognitivo: o estoque de indícios e de significantes que a pessoa recebe, emite e manipula no ciclo das infracomunicações pode tornar-se superabundante".

Já a ancoragem se refere à incorporação de determinado elemento à realidade social, isto é, a associação de novos objetos a um sistema de saberes anterior, já existente e consolidado, mediante algumas adaptações. Para Sá (1998, p. 37), a ancoragem "consiste na integração 
cognitiva do objeto representado - sejam ideias, acontecimentos, pessoas, relações etc. - a um sistema de pensamento social preexistente e nas transformações implicadas".

De acordo com Moscovici (2015, p. 71), a objetivação é a concretização do objeto de representação em uma imagem, e a ancoragem o enraizamento da representação no mundo social, relacionando esse objeto com as práticas sociais dos grupos. Esses processos estão intrinsicamente ligados um ao outro e são modelados por fatores sociais. Neste estudo buscamos indicar particularmente a objetivação, em que uma das fases se dá pela presença de um modelo, ou núcleo figurativo. A objetivação consiste em "descobrir a qualidade icônica de uma ideia", concretizando-a através da imagem, onde a abstração é materializada. Segundo Alves-Mazzotti (2002, p. 18), esse núcleo é:

[...] uma construção estilizada e descontextualizada do objeto que, absorvendo o excesso de significações, esquematiza, concretiza e coordena os elementos da representação, proporcionando uma imagem facilmente exprimível do objeto e passando a constituir o próprio real para aqueles que os constroem.

De acordo com Alves-Mazzotti (2008, p. 24) a identificação da objetivação e da ancoragem nos processos de formação das representações sociais é a maior contribuição do trabalho de Moscovici à Psicologia Social, já que "permite compreender como o funcionamento do sistema cognitivo interfere no social e como o social interfere na elaboração cognitiva".

É no resultado da transformação de um conceito ou uma ideia em algo concreto que se forma o modelo figurativo da representação social, privilegiado nesse estudo. Ele torna perceptível a estrutura conceitual de maneira que os indivíduos possam perceber conformações subjetivas típicas de conceitos, tornando o objeto acessível. Segundo Moscovici (2012, p. 114): "Quando o modelo é descrito como figurativo, é não só uma maneira de classificar as informações, mas o resultado da coordenação que caracteriza cada termo da representação". São esses aspectos que a pesquisa buscará demonstrar a seguir.

\section{PROCEDIMENTOS METODOLÓGICOS}

A pesquisa, de cunho qualitativo (ALVES-MAZZOTTI; GEWANDSZNAJDER, 1998), foi desenvolvida junto a dois grupos de empresários de moda que possuem confecção no Estado do Rio de Janeiro e que têm ou já tiveram estagiários ou profissionais graduados em moda em suas empresas. Um grupo foi constituído de dez empresários com formação no Curso de Graduação em Moda. O outro grupo, também constituído de dez pessoas, não teve essa formação. $O$ projeto foi submetido ao Comitê de Ética em Pesquisa (CEP) da Universidade Estácio de Sá, CAAE 70200017500005284 , e aprovado por meio do parecer 2215756.

Foram realizadas entrevistas nos municípios do Rio de Janeiro, de Caxias, de Petrópolis e de Teresópolis. O Estado do Rio de Janeiro foi escolhido porque comporta universidades que promovem o curso de graduação em Moda há mais de 25 anos. As entrevistas foram semiestruturadas, cabendo ao entrevistador a condução flexível, garantindo que não ocorressem grandes desvios do tema, mas possibilitando que os entrevistados expusessem suas opiniões e vivências.

O critério de escolha dos entrevistados pela da técnica "bola de neve", utilizada em pesquisas sociais (BALDIN, MUNHOZ, 2011, p. 332). Cada empresário indicava um outro para participar da pesquisa. A cada entrevistado a "bola de neve" crescia, sendo possível trabalharmos com 20 pessoas no decorrer de três meses. 
Algumas entrevistas foram realizadas nas próprias instalações fabris, outras em loja das empresas, outras em cafés e algumas ainda nas residências dos entrevistados. 0 motivo dessa diversidade de locais foi a dificuldade na disponibilidade de cada entrevistado. Todas as entrevistas foram gravadas e posteriormente transcritas. Os entrevistados foram enumerados de E1 a E20: E1 a 10 para graduados em Moda, e E11 a E20 para não graduados em Moda.

O material foi analisado com apoio da análise de conteúdo, a qual contempla a exploração das comunicações, em que as negociações sociais se dão por meio das interações levando em consideração experiências dos sujeitos entrevistados, suas crenças e valores (BARDIN, 2011).

A análise de conteúdo foi dividida em três etapas: pré-análise, fase exploratória e fase de interpretação dos resultados (BARDIN, 2011). A pré-análise é caracterizada pela exploração do material coletado nas entrevistas e o tratamento desses resultados com inferências do entrevistador. Ela inicia-se por uma leitura flutuante das falas a fim de conhecer os aspectos mais relevantes citados nas entrevistas, tendo foco nos objetivos da pesquisa. A leitura flutuante foi feita várias vezes até a extração da essência das falas dos entrevistados.

$\mathrm{Na}$ fase exploratória foram propostos temas e, a partir desses, definidas categorias (indicadores apontados com regularidade nas entrevistas, que aparecem nos discursos dos sujeitos e que permitem classificá-los de acordo com um tema) e subcategorias (desdobramentos das categorias). A partir dessas definições, foram criados códigos identificadores e quantificados para cada categoria e subcategoria visando facilitar a posterior tabulação dos dados das entrevistas.

$\mathrm{Na}$ etapa de interpretação dos resultados foram observadas convergências e divergências nas falas dos entrevistados, buscando-se encontrar indícios de representações sociais construídas pelos dois grupos a respeito da formação do graduado em Moda. Com base nessas reflexões foi possível propor um modelo figurativo da representação social para cada grupo.

\section{RESULTADOS E DISCUSSÕES}

Serão apresentados nesse item os resultados referentes aos dois grupos de empresários, com base em aspectos da análise de conteúdo e em duas questões que compuseram o roteiro de entrevista: 1) "Se você fosse diretor (a) de uma escola de formação em Moda, como seria o seu curso?" e 2) "O que vem à sua mente quando eu digo primeira imagem do graduado em Moda?". O conjunto dessa análise possibilitou a proposta de um modelo figurativo da representação social da formação do graduado em Moda para cada grupo, considerando que "ao penetrar no meio social como expressão do real, o modelo figurativo se torna então natural, utilizado como se fosse copiado diretamente dessa realidade" (MOSCOVICI, 2012, p. 115).

\subsection{Grupo I - Empresários graduados em Moda}

Para esse grupo foram identificadas duas unidades temáticas: "Formação em Moda na graduação" e "Formação em Moda no trabalho". Serão destacados aqui elementos extraídos das categorias em que os empresários se expressam sobre sua relação com o trabalho.

Vários escolheram fazer graduação em Moda porque já atuavam na área e/ou foram infuenciados por familiares que trabalhavam como costureiras ou modelistas. A formação acadêmica foi apresentada como um aperfeiçoamento, como sugere o relato de uma empresária que trabalhava com seu marido e, em seguida, optou por ingressar em um curso de nível superior na área de Moda: "Ele cortava e eu costurava, e nós dois arrematávamos à noite e nós dois 
vendíamos na minha própria casa, e assim a gente ficou cinco anos. Então, eu fui fazer Moda e ele foi fazer Direito" (E7).

O "preconceito" em relação à moda foi categoria relevante na pesquisa, talvez devido ao fato de estar ligada ao efêmero, ao consumismo (LIPOVETSKY, 2008), como expressam a fala a seguir: "Comecei a pensar em fazer Moda desde o início, mas meus pais eram um pouco contra. Eles achavam que não era curso, que eu ia morrer de fome" (E2).

Outra categoria sinalizada pelo grupo foi a "necessidade de educação continuada", com busca de saberes, tendo em vista a rapidez de mudanças de tecnologia e de processos pelos quais estamos passando. De acordo com os entrevistados, a ampliação dos conhecimentos se faz presente em todas as formações, incluindo o campo da moda.

A relação entre formação e mercado de trabalho" também foi mencionada. Para E7:

Acho que as faculdades, também tem essa coisa de inchar, né? Foram querendo botar tanto aluno pra fazer Moda. Eu não sei se o mercado, a gente acabou tendo uma crise muito grave e fez com que o mercado tenha ficado muito reduzido e é muita gente pedindo emprego, formados em Moda, que fizeram bons cursos. Foram bons alunos e não conseguem se encaixar" (E7).

Cinco entrevistados consideram a "grade curricular insuficiente", indicando falta de disciplinas consideradas estratégicas, como Empreendedorismo e Prática na Formação do Graduado. Alguns se referiram a "práticas insuficientes", o que leva o profissional a obter resultados insatisfatórios quanto se insere no ambiente de trabalho.

A maioria dos entrevistados considerou insuficiente seu aprendizado na faculdade e criticou os estágios oferecidos. As falas mostraram que a aprendizagem se dá por duas vias. Uma promovida pela academia e outra, no exercício do trabalho, nas organizações. Para exemplificar, destaca-se a fala de E4: "Independente da formação. Porque se a pessoa tem um perfil [...] $O$ resto, aprende na prática. O principal é ter um perfil e conhecimento básico". A fala de E9 também é significativa: "E aí quando o aluno chega, no chão de fábrica, como a gente costuma dizer, ele está muito cru. Então até pra conseguir um estágio, é difícil porque ele não tem o menor jogo de cintura".

Em complementaridade às posições acima, em que os empresários expressam relações entre formação na área e trabalho, o Quadro 1 apresenta respostas referentes à pergunta: "Se você fosse diretor(a) de uma escola de formação em Moda, como seria o seu curso?".

Esses comentários indicam como o empresário com formação em Moda percebe o desenvolvimento do curso, apontando sugestões técnicas, culturais, infraestruturas, mercadológicas e processo seletivo. A melhoria na formação do profissional de Moda, privilegiando a relação mais estreita com o mercado de trabalho, seria a principal ação a ser implementada pelas universidades do Estado do Rio de Janeiro que promovem o curso, de acordo com os entrevistados.

Associado ao que foi descrito anteriormente, o Quadro 2 mostra imagens que os empresários do Grupo 1 têm do graduado em Moda, tanto positivas quanto negativas, decorrentes da questão: "O que vem à sua mente quando eu digo "primeira imagem do graduado em Moda?". 
QUADRO 1 - "Se você fosse diretor (a) de uma escola de formação em Moda, como seria o seu curso?" - Grupo 1

\begin{tabular}{|c|c|}
\hline Entrevistado & Comentário \\
\hline E1 & O curso de Moda poderia ter mais um tempo de prática. \\
\hline E2 & $\begin{array}{l}\text { Separar quem quer ser estilista e quem quer trabalhar com jornalismo [...] trabalhar com } \\
\text { estudante como se fosse uma empresa de moda. Então a gente divide em grupos. Cada estilista, } \\
\text { cada aluno vai ser responsável por uma área. }\end{array}$ \\
\hline E3 & $\begin{array}{l}\text { Essa sinergia com o mercado é muito importante [...] parte do corpo } \\
\text { docente tem que ter, estar no mercado. }\end{array}$ \\
\hline E4 & $\begin{array}{l}\text { Investiria mais na parte técnica de fibras têxteis, conhecimento de tecidos. Ir em uma indústria } \\
\text { de tecelagem pra saber. Ir mais para a prática e não só na teoria [...]a parte de gestão é } \\
\text { fundamental. Teria que incluir e talvez eu fizesse parcerias com empresas para fazer intercâmbio } \\
\text { de estágio, porque a prática é muito importante [...]Talvez fatiasse o curso. }\end{array}$ \\
\hline E5 & $\begin{array}{l}\text { Eu faria um trabalho de conhecimento de tecido [...] faria das Artes também, porque quando } \\
\text { você volta para a parte intelectual desse aluno, ele consegue perceber aquilo que vai dar certo na } \\
\text { criação dele. E aí, eu estou falando de estruturar mesmo a sua criação. [...] As viagens são } \\
\text { importantes, a pesquisa de campo também é muito importante, mas também eu acredito que } \\
\text { essa prática, de você cada vez mais, junto a esses empresários. }\end{array}$ \\
\hline E6 & $\begin{array}{l}\text { Melhoraria a parte técnica sem dúvida. A parte técnica é a base pra você ter um bom profissional } \\
\text { de Moda. A explicar o que é um tecido, o que é explicar o que é urdume, trama. Como faz, como é, } \\
\text { como não é. É como você faz para cortar. O fio. O que você faz pra importância da modelagem. A } \\
\text { importância de uma graduação bem-feita. }\end{array}$ \\
\hline E7 & $\begin{array}{l}\text { Eu criaria um hábito de que o aluno visitasse um museu ou uma galeria } \\
\text { de arte uma vez por mês. Tinha que ser um hábito. Tinha que fazer parte do currículo da } \\
\text { escola. [...] estaria estimulando ele, através de uma leitura, de uma exposição de arte, através } \\
\text { de um filme que fizesse essa pessoa pensar. Pensar, pensar. }\end{array}$ \\
\hline E8 & $\begin{array}{l}\text { Seria muito mais voltado para a Criação e pra essa parte artística. [...] } \\
\text { investir em um profissional [referindo ao professor] que é apaixonado por aquilo. }\end{array}$ \\
\hline E9 & $\begin{array}{l}\text { Se eu me proponho a organizar um curso eu tenho que preparar essas pessoas para esse } \\
\text { mercado, então eu tenho que organizar da melhor forma, de forma que aquela pessoa tenha } \\
\text { condição de chegar ao final do curso e saber que ela possa enfrentar, assumir um cargo dentro } \\
\text { de uma empresa. [...] investiria no processo de seleção, pois iniciar no curso hoje em dia se } \\
\text { tornou muito banal. }\end{array}$ \\
\hline E10 & $\begin{array}{l}\text { Daria empreendedorismo [...] Eu colocaria pessoas do mercado pra dar aula. [...] o mercado não } \\
\text { vai se adaptar à academia. Então acho que a academia é que tem que se adaptar ao mercado. Não } \\
\text { adianta eu ficar nas teorias lindas e tudo funciona porque não funciona [...] ensinar trabalhar em } \\
\text { equipe e a melhorar o trabalho dos outros. }\end{array}$ \\
\hline
\end{tabular}

Fonte: As autoras

QUADRO 2 - Imagens do Graduado em Moda para o Grupo 1 - Aspectos Positivos e Negativos (em ordem alfabética)

\begin{tabular}{|l|l|}
\hline Aspectos Positivos & Aspectos Negativos \\
\hline Antenado (E6;E9) & Alucinado (E4) \\
\hline Artista (E8) & Autoritário e "nariz em pé" (E9) \\
\hline Bom gosto (E9) & Consumista (E3) \\
\hline Criativo (E6; E8) & Despreparado (E4) \\
\hline Curioso (E6) & Egocêntrico (E3; E10) \\
\hline Dinâmico (E6) & Inexperiente (E7; E10) \\
\hline Super ligado em cores e formas (E8) & Não entende de gestão (E4) \\
\hline Talentoso (E1) & Raso (E7) \\
\hline Versátil (E5) & Superficial (E2) \\
\hline
\end{tabular}

Fonte: As autoras 
As qualidades apontadas servem de base para o desempenho na área de desenvolvimento de produtos, onde se faz necessária a conexão com o mundo, a criatividade e o talento. Já os aspectos negativos podem comprometer a inserção no mercado de trabalho dos graduados. A graduação em Moda, para os entrevistados, também parece não privilegiar uma melhor relação entre o conteúdo programático a ser ensinado.

Os dados expostos permitiram uma hipótese interpretativa do modelo figurativo dos empresários com formação em Moda sobre a formação do graduado nessa área, ilustrado na Figura 1.

Conforme já mencionado, o modelo figurativo expressa o abstrato tornando-se, na representação, uma tradução do objeto. Ele promove o entendimento através de um esquema da organização dessa representação, em que se dá a materialização do processo de construção pelo qual as representações sociais são estruturadas (MOSCOVICl, 2012).

O elemento que coordena a representação desse grupo sobre a formação do graduado em moda é a "insuficiência na formação". Está assim objetivada a representação investigada, associada a "aprendizagem com pouca prática", "curso ainda recente", "alunos pouco envolvidos com o curso", "conhecimento teórico deficitário", "pouca empregabilidade".

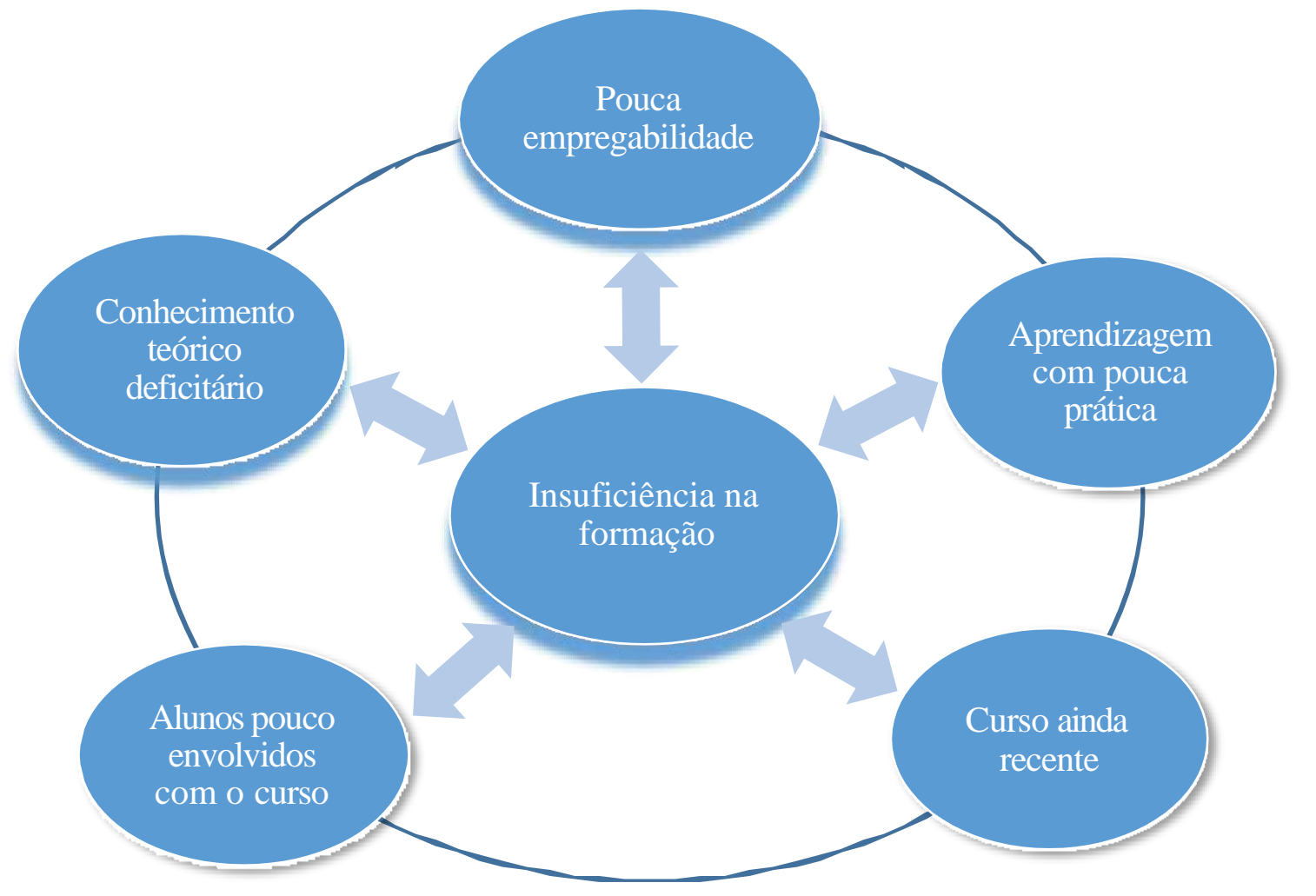

Fonte: As autoras

Figura 1 - Modelo Figurativo da representação social da formação do graduado em Moda por empresários (Grupo 1) - uma hipótese interpretativa.

Falas de empresários desse grupo fortalecem a organização do modelo figurativo. Por exemplo: "É um pouco triste falar isso, mas eu acho que a formação foi muito superficial" (E2); "Uma interação tão maior. Essa coisa mercado e universidade. Eu acho que falta isso no Brasil em muitos cursos, mas eu estou falando de Moda" (E1); "Mas eu acho que faltou [...] muita coisa eu aprendi na prática. A faculdade não me preparou para essa parte de gestão e pra parte um pouco 
mais técnica" (E4); "Essa falta de realidade que as faculdades, os cursos de Moda trazem para dentro de sala de aula" (E10).

\subsection{Grupo 2 - Empresários sem graduação em Moda}

Para o grupo de empresários não graduados em Moda, a análise apontou duas unidades temáticas: "O graduado em Moda no trabalho" e "O campo da Moda no trabalho". No Grupo 2, os empresários expressam as razões que os levaram à construção de suas empresas. Oito se declararam "sem conhecimento anterior da área", indicando que a maioria não tinha formação em moda quando iniciou suas empresas, as quais foram abertas a partir das oportunidades de mercado da época. Ao buscarem conhecimentos na área após a montagem da empresa, relatam: "Desenho de moda, de gerência de produção. Eu tenho um bolinho de diplomas" (E14); "De cursos, frequentei vários [...] participei de palestras..." (E17).

A "influência familiar" também foi mencionada por sete sujeitos. Como para o Grupo 1, aparece no Grupo 2 uma tradição na área de moda que é passada entre gerações, apontando a família como geradora de influências na escolha da profissão a ser seguida.

Quatro participantes mencionam "aprender no cotidiano do trabalho". Relatam conhecimentos que forjaram sua trajetória empresarial: "Eu que comprava os tecidos. Elas [as costureiras] me davam uma amostra [...] e eu fui aprendendo, aprendendo (E12).

No Grupo 2, as fontes de inspiração são múltiplas, como viagens e acesso a referências do mundo virtual, por exemplo, E20: “A minha irmã que é a responsável pela criação. Minha mãe e minha irmã [ambas sem formação em Moda]. Mas como é que elas criam? Como é o sistema em termos de criação? Elas viajam para a Europa. Hoje em dia é muita internet, elas viajam para a Europa e trazem o máximo de que podem trazer. [...] e elas vão criando e adequando ao que nosso cliente está querendo".

Em relação ao Grupo 1, o Grupo 2 faz mais críticas aos cursos de Moda, tecendo comentários sobre experiências com graduados que tiveram em suas organizações e também sobre cursos e palestras que assistiram. Por exemplo: "Falava coisas muito técnicas, da trama, do urdume, e que provavelmente talvez a pessoa não fosse usar se não fosse trabalhar numa tecelagem [...], eu acho que deveria ter uma aproximação maior com esse mundo do varejo, com a venda e da pessoa..." (E13); "Parte de gestão não existe mais nos cursos de Moda. [...] Nem montagem de preço" (E14); "Falta no curso uma excelente cadeira de gestão de negócio" (E16); "Eu acho que a formação delas na faculdade é muito teórica" (E17).

Quanto ao desempenho dos graduados, várias críticas foram tecidas. Para o Grupo 2, os graduados no curso não sabem se posicionar adequadamente fora do meio acadêmico. Por exemplo: "Até por isso que os estilistas têm uma certa fama de... de ser tudo de nariz em pé, autoritário" (E9); "Os alunos se frustram porque eles acham que vão trabalhar tomando champanhe de salto alto o dia inteiro" (E10).

Sobre contribuições de profissionais da Moda em seus negócios, alguns exemplos podem ser citados: "Acho que nesse sentido, essas [não graduadas com experiência] me ajudaram mais do que as que vieram com a bagagem, com a formação, especificamente na faculdade (E17); "Porque minha grande massa criativa é não ser pessoas formadas, que começaram lá e sabem todo o processo. Eu valorizo mais esse tipo de crescimento" (E18).

Os empresários do Grupo 2 também se referem ao aprendizado na prática diária da empresa. Por exemplo, E14 menciona a dificuldade do aluno em formar o preço do produto, pois não aprendeu como calculá-lo no decorrer do curso: “A parte de gestão não existe mais nos cursos 
de Moda. Fica bem deficiente porque eles não têm aquela noção do que vou botar aqui dentro. Nem montagem de preço".

Para esse grupo, seria desejável para o desenvolvimento do futuro profissional o período de estágio, de aplicação dos conhecimentos adquiridos nas disciplinas. Por exemplo: "Devia fazer parte de um currículo ter que fazer o estágio numa loja por três meses pois lá se aprende tudo e muito" (E13); "[...] Tem que ter um estágio aí de um ano mesmo enfurnado em alguma oficina boa, grande, pra poder absorver esse conhecimento" (E16).

Em complementaridade às posições acima, o Quadro 3 apresenta respostas referentes à pergunta: "Se você fosse diretor (a) de uma escola de formação em Moda, como seria o seu curso?".

QUADRO 3 - "Se você fosse diretor (a) de uma escola de formação em Moda, como seria o seu curso?" - Grupo 2

\begin{tabular}{|c|c|}
\hline Entrevistado & Comentário \\
\hline E11 & $\begin{array}{l}\text { Investir na prática. Fazer uns treinamentos específicos em cada tipo de serviço, de } \\
\text { operações ou moda. }\end{array}$ \\
\hline E12 & $\begin{array}{l}\text { O trabalho que é feito na escola, ele tem que ser direcionado para alguma empresa. Uma } \\
\text { grande empresa que fizesse uma parceria com a Escola. Para que aqueles profissionais } \\
\text { começassem a desenvolver produtos que eles também vissem saindo lá na loja. }\end{array}$ \\
\hline E13 & $\begin{array}{l}\text { Formação cultural. Um bom português. Noção de produção, de modelagem, estudo de } \\
\text { mercado, antropologia e tentar entender para onde o mercado está caminhando, estágios } \\
\text { no mercado de trabalho. Eu convidaria empresários para trocar, pra falar. }\end{array}$ \\
\hline E14 & $\begin{array}{l}\text { A aula de origami e de anatomia que ajudariam na modelagem, na criação, na } \\
\text { elaboração das peças e tudo mais. }\end{array}$ \\
\hline E15 & Eu mandaria os professores aprenderem lá fora. Pra saber o que é dar aula de Moda. \\
\hline E16 & $\begin{array}{l}\text { Um excelente laboratório de criação, de gestão financeira, gerenciamento de vendas. [...] } \\
\text { teria que ser cursos práticos. }\end{array}$ \\
\hline E17 & Eu aumentaria as horas deles no chão de fábrica antes de se formarem. \\
\hline E18 & $\begin{array}{l}\text { Trocaria as salas por máquinas de costura e mesa de corte. Acho muito importante } \\
\text { entender o processo. [...] ter noção financeira e ter uma noção do que é viável e do que } \\
\text { não é viável. Eu sinto falta do prático. Do realizável. }\end{array}$ \\
\hline E19 & Eu acho que poderia ter mais umas oficinas de carnaval. \\
\hline E20 & Dar muita informação para a pessoa e ter uma excelente biblioteca. \\
\hline
\end{tabular}

As falas do Quadro 3 indicam forte tendência a enfatizar o cunho prático do curso. Como sugestão, o grupo indica a realização de estágios em empresas do segmento da moda, incluindo o varejo; oficinas instaladas dentro das próprias faculdades, que seriam espaços para os alunos aplicarem os conceitos teóricos constantes nos currículos.

Associado ao que foi descrito anteriormente, o Quadro 4 mostra imagens que os empresários do Grupo 2 têm do graduado em Moda, tanto positivas quanto negativas, decorrentes da questão: "O que vem à sua mente quando eu digo 'primeira imagem do graduado em Moda?". 
ROGRIGUES, Rose Mary Mariano; LIMA, Rita de Cássia Pereira

Representações sociais da formação do graduado em Moda por empresários do setor

QUADRO 4 - Imagens do Graduado em Moda para o Grupo I - Aspectos Positivos e Negativos (em ordem alfabética)

\begin{tabular}{|l|l|}
\hline Aspectos Positivos & Aspectos Negativos \\
\hline Bom gosto (E11) & Desconectado (E15) \\
\hline Dedicado (E19) & Frustrado (E18) \\
\hline Esforçado (E14) & Impaciente (E18) \\
\hline Mestre (associou “dom" à “técnica”) (E12) & Sem “pé no chão" (sonhador) E13, E16, E17, E18 \\
\hline Perceptivo (E20) & \\
\hline
\end{tabular}

Fonte: As autoras

Os dados expostos permitiram uma hipótese interpretativa do modelo figurativo dos empresários sem formação em Moda sobre a formação do graduado nessa área, ilustrado na Figura 2.

O elemento que coordena a representação desse grupo sobre a formação do graduado em Moda é "aprendizagem acontece no trabalho", objetivando a representação investigada. Este termo associa-se a "empregabilidade não depende da graduação", "formação insuficiente", "graduado sem prática", "formação não direcionada para a empresa".

Figura 2 - Modelo Figurativo da representação social da formação do graduado em Moda por empresários - Grupo II

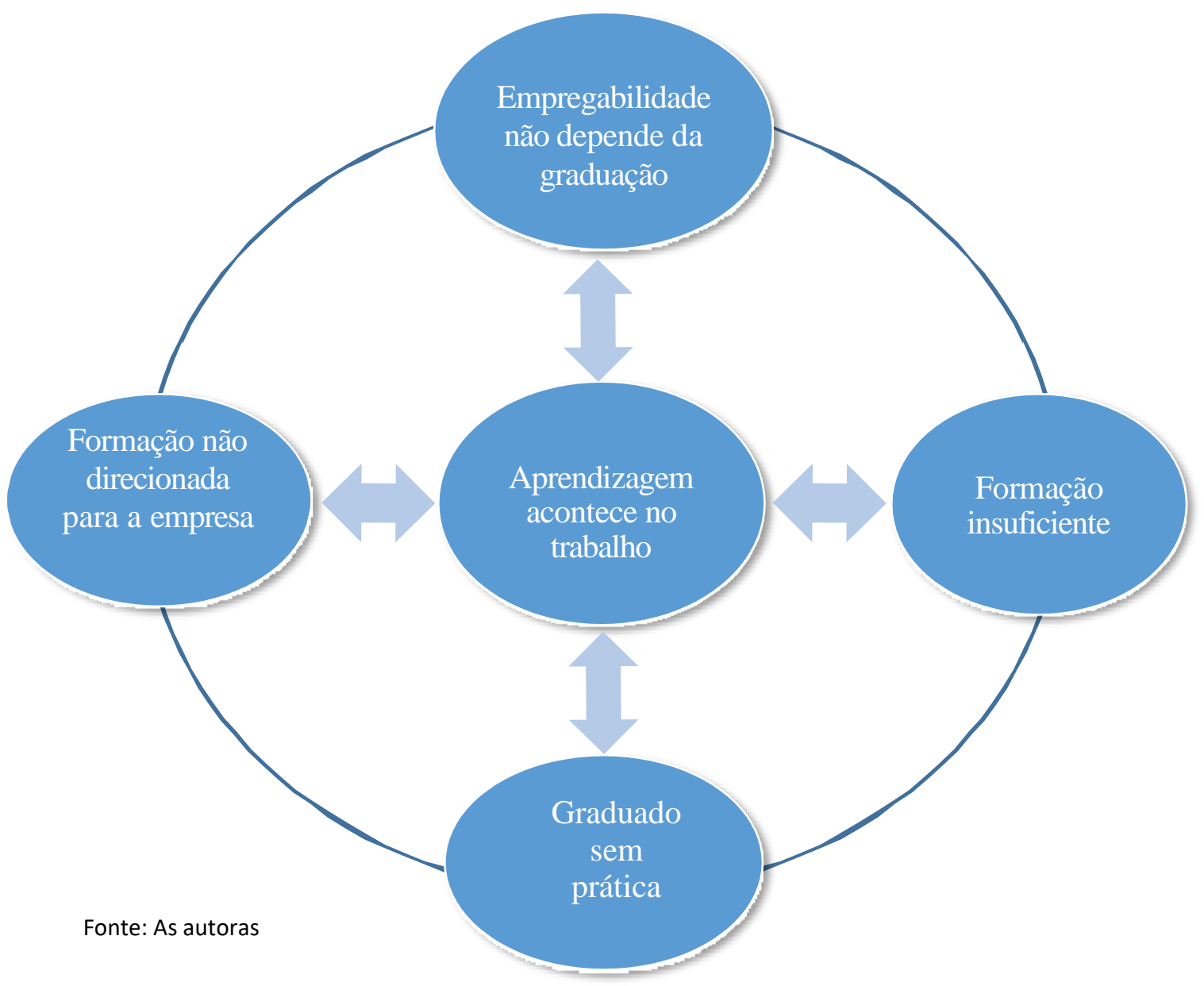

Figura 2 - Modelo Figurativo da representação social da formação do graduado em Moda por empresários (Grupo 2) - uma hipótese interpretativa. 
Todos os entrevistados sem formação na área acreditam que a prática é mais relevante do que o conhecimento teórico apresentado pelos graduados. As falas a seguir exemplificam: "Eu não considero o diploma um diferencial para contratar uma pessoa que vem procurar emprego comigo" (E17); "Ela era uma estilista assim bem de mão cheia, mas ela não se formou em estilista" (E20).

De acordo com Torres (2010, p. 63), "os empresários de moda do Rio de Janeiro preferem contratar pessoas sem formação e mais antigas no mercado de trabalho". Segundo a autora, eles ainda não compreendem o papel do design dentro de suas empresas.

As imagens do graduado em Moda expressas pelos empresários de ambos os grupos demonstram que novos estudos poderiam ser desenvolvidos a fim de criar debates que poderão gerar benefícios para a formação em Moda, pois são os formados que representam inicialmente a instituição e o curso no mundo do trabalho, com potencial para estabelecer diálogos entre essas duas partes.

\section{CONSIDERAÇÕES FINAIS}

O estudo com empresários da Moda, investigando suas representações sociais sobre a formação do graduado neste curso, indicou uma diferença principal. Para os participantes do Grupo 1, com formação em Moda, essa representação se objetivou na "insuficiência da formação no Ensino Superior". E para os participantes do Grupo 2, sem formação na área, a representação se objetivou no "aprendizado no trabalho". Embora os dois grupos critiquem a formação oferecida nos cursos de Moda, no Grupo 1 há a proposta de melhorá-la para a contratação de profissionais no mundo do trabalho, enquanto para o Grupo 2 essa formação é desnecessária para atuar no mercado da Moda.

A TRS foi fundamental para a identificação de significados sobre a formação nos cursos de graduação em Moda pelos dois grupos, por meio dos modelos figurativos da representação social (MOSCOVICl, 2012). Conforme já exposto, o modelo figurativo corresponde a uma fase do processo de objetivação em que uma ideia é materializada pelo grupo, organizando e coordenando seu discurso. A pesquisa aqui apresentada apresentou esse recorte, que auxilia na compreensão da representação social. No entanto, para um estudo mais completo de representação social, seria necessário associar a objetivação ao processo de ancoragem, que mostra a inserção do objeto de representação no universo social e cultural dos grupos. Trata-se de um tema que poderá ser desenvolvido futuramente.

Importante ressaltar que os modelos figurativos propostos são considerados como hipóteses interpretativas a partir dos dados gerados pelos vinte empresários, dentro do contexto no qual eles podem elaborar representações sociais sobre a formação do graduado em Moda. Neste caso também é desejável continuidade por meio de outras pesquisas que também abordem o modelo figurativo.

Em seu conjunto, a pesquisa mostrou relações entre a formação acadêmica oferecida por cursos de graduação em Design de Moda e as demandas do mundo do trabalho. O reconhecimento da relevância da formação acadêmica apontada pelo Grupo 1, atrelada à insuficiência na formação, é importante para discussões entre universidades e empregadores potenciais. O termo "aprendizagem acontece no trabalho", objetivado pelo Grupo 2, aponta que a formação superior na área de Moda não é condição imprescindível para o mercado de trabalho no momento de contratações. Trata-se de um resultado que também demanda maior aproximação entre cursos de Moda e empresariado. 
As cristalizações das representações dos empresários do Rio de Janeiro a respeito da formação do graduado em Moda foram primordiais para a realização dessa pesquisa, podendo incitar outras reflexões que permitam aproximações mais consistentes entre academia e mundo do trabalho. Acreditamos que os resultados apresentados podem contribuir para que exista uma maior comunicação entre universidade e empresariado, sem deixar de considerarmos, obviamente, que a universidade precisa manter seu perfil crítico, não deixando de ser um espaço acadêmico de reflexão e debate.

\section{REFERÊNCIAS}

ABRAVEST - Associação Brasileira da Indústria Têxtil. Site: http://abravest.org.br/site/. Acesso em 23 abr. 2017.

AGUIAR, G. C. O. Cursos superiores de moda no Brasil: regulamentações, evoluções e perspectivas. In: 11으 Colóquio de Moda - 8a Edição Internacional 2ํ Congresso Brasileiro de Iniciação Científica em Design e Moda, 2015. Informações obtidas em http://www.coloquiomoda.com.br/anais/anais/11-Coloquio-de-Moda 2015/ARTIGOS- Acesso em 3 jun. 2016.

ALMEIDA, A.; SANTOS, F.; TRINDADE, Z. Ancoragem: notas sobre consensos e dissensos. In: ALMEIDA, A.; SANTOS, F.; TRINDADE, Z. Teoria das representações sociais: 50 anos. Brasília: Technopolitik, 2014.

ALVES-MAZZOTTI, A. J. Representações sociais: aspectos teóricos e aplicações à educação. Revista Múltiplas Leituras, v.1, n. 1, p. 18-43, jan. / jun. 2008.

ALVES-MAZZOTTI, A. J. A abordagem estrutural das representações sociais. In: Psicologia da Educação: Revista do Programa de Estudos Pós-Graduados, São Paulo, 14/15, 1ㅇ e 2ㅇ sem. de 2002.

ALVES-MAZZOTTI, A. J.; GEWANDSZNAJDER, F. O método nas ciências naturais e sociais: pesquisa quantitativa e qualitativa. São Paulo: Pioneira, 1998.

BALDIN, N.; MUNHOZ, E. M. B. Snowball (bola de neve): uma técnica metodológica para pesquisa em educação ambiental comunitária. $X$ Congresso Nacional de Educação. I Seminário Internacional de Representações Sociais, Subjetividade e Educação. Pontifícia Universidade Católica do Paraná. Curitiba. Paraná. 2011. Informações obtidas em http://educere.bruc.com.br/CD2011/pdf/4398_2342.pdf. Acesso em 15 set. 2017.

BARDIN, L. Análise de conteúdo. São Paulo: Edições 70, 2011 (edição revista e ampliada).

BORGES, M. Representações Sociais de alunos e professores do curso de Design de Moda sobre a Moda: 2014. Dissertação (Mestrado em Educação). Programa de Pós Graduação em Educação, Universidade Estácio de Sá, Rio de Janeiro, 2014.

BRASIL, Ministério da Educação. Conselho Nacional de Educação. Leis de Diretrizes e Bases, 2004. 
CALANCA, D. História social da moda. 2ạ. ed. Tradução de Renato Ambrosio. São Paulo: Editora Senac. São Paulo, 2011.

CHRISTO, D. C. Designer de moda ou estilista? Pequena reflexão sobre a relação entre noções e valores do campo da arte, do design e da moda. In: PIRES, Dorotéia Baduy (Org.). Design de moda - olhares diversos. São Paulo: Estação das Letras, 2008.

CUNHA, L. A. O ensino de ofícios artesanais e manufatureiros no Brasil escravocrata. São Paulo: UNESP, 2000.

HOLLANDER, A. O Sexo e as Roupas. A evolução do traje moderno. Tradução de Alexandre Tort; revisão técnica de Gilda Chataignier. Rio de Janeiro: Rocco, 1996.

LIPOVETSKY, G. O império do efêmero: a moda e seu destino nas sociedades modernas. Tradução: Maria Lúcia Machado. São Paulo: Companhia da Letras, 2008.

MARQUES, C. T. Do estilismo ao design: os currículos do bacharelado em moda da Universidade Federal do Ceará: 2014. 195 p. Tese (Doutorado), Universidade Federal do Ceará, Faculdade de Educação, Programa de PósGraduação em Educação Brasileira, Fortaleza, 2014.

MOSCOVICl, S. A Psicanálise, sua imagem e seu público. Tradução de Sonia Fuhrmann. Petrópolis: Vozes, 2012.

MOSCOVICI, S. Representações sociais: Investigações em psicologia social. Tradução de Pedrinho A. Guareschi. Petrópolis, 11ạ. Ed.: Vozes, 2015.

SÁ, C. P. A construção do objeto de pesquisa em representações sociais. Rio de Janeiro: Ed. UERJ, 1998.

TORRES, A. C. C. Representações sociais de alunos e professores do curso de moda sobre o mercado consumidor: 2010. 104 p. Dissertação (Mestrado em Educação) - Programa de PósGraduação em Educação, Universidade Estácio de Sá, Rio de Janeiro, 2010. 